\title{
Unsteady Burning Rates of Small Pool Fires
}

\author{
HIROSHI HAYASAKA \\ Faculty of Engineering, Hokkaido University \\ Kita-ku, N13, W8, Sapporo, 060, Japan
}

\begin{abstract}
This paper experimentally and theoretically shows why experiment on small pool fires yield different burning rates. Small pool fire tests were carried out to examine the effect of fuel temperature and tank temperature on the burning rate during unsteady combustion. In these experiments, the fuel level in the tank was not controlled. It was found that : 1.) there are three processes associated with the fuel temperature change ; 2.) the three processes are called preheating, transition and boiling ; 3.) the burning rates of heptane and kerosene depend on the fuel temperature and they increase their burning rates about $60 \%$ and $30 \%$ respectively as the three processes are traversed ; 4.) methanol did not change its burning rate. Finally, the reason for various burning rate changes of small pool fires are clearly explained by the calculation of fuel evaporation using measured burning rates and fuel temperatures.
\end{abstract}

KEYWORDS : Pool flame, Burning rate, Evaporation heat, Heat balance

\section{INTRODUCTION}

For many years, fire researchers [1] [13] have been studying the burning rate, flame height and radiated heat from flames of pool fires. The burning rate is one of the most important characteristics of pool fires. But burning rates, measured using the same fuel and tank diameter, often differ from one another [6] . The reason for this observed difference in burning rate is 
not clear at present.

In this paper, burning rates measured during unsteady combustion of small pool fires using three different fuels are discussed. Unsteady combustion is obtained by a batch test in which the fuel level in the tank decreases after ignition. The burning rates, the fuel temperature, and the tank temperature were measured for three different fuels. From the results, three processes in the unsteady combustion of pool fires were defined using the fuel temperature curves. The three processes are called preheating, transition and boiling. The heptane and kerosene flames increased their burning rates about $60 \%$ and $30 \%$ respectively when burning rates during preheating and boiling are compared. On the other hand, the methanol flame showed a constant burning rate. One reason for this different trend in burning rate is explained by using the fuel temperature, the tank temperature and the heat of evaporation of each fuel.

\section{EXPERIMENT}

The experimental setup is shown in Fig. 1. A small stainless steel tank of $50.5 \mathrm{~mm}$ inside diameter, depth $11 \mathrm{~mm}$ and wall thickness 0.6 $\mathrm{mm}$ was used for the pool fire tests. A slate plate with thickness $6.2 \mathrm{~mm}$ was inserted between the tank and an electric balance. Heptane, kerosene, and methanol were used as test fuels. Important fuel properties [14] for the three fuels are listed in Table 1.

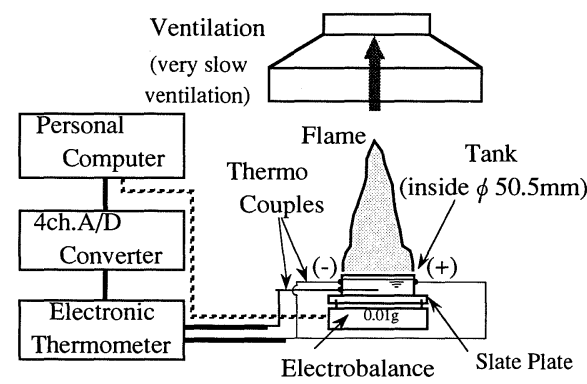

At the start of an experiment, fuel was fed into the tank so as to make the burner freeboard height almost zero. After ignition, the methanol fire produced a blue flame and the other fires had yellow flames as commonly observed. The burning rate (mass loss rate) was measured by the electric balance. Tank temperature was measured by a chromel-alumel thermocouple made of $0.1 \mathrm{~mm}$ wire diameter that was divided into two lines and welded separately at two points near the top edge of the tank. The distance between the chromel and alumel to tank junctions was almost the same as the tank diameter. Thus we could measure the tank

Fig.1 Schematic Experimental Arrengement . for Small Pool Flames

Table 1 Fuel Properties [6] , [14]

\begin{tabular}{c|c|c|c}
\hline & Heptane & Methanol & Kerosene \\
\hline $\begin{array}{c}\text { Heat of } \\
\text { Combustion } \\
(\mathrm{MJ} / \mathrm{kg})\end{array}$ & 41.3 & 20.5 & 41.1 \\
\hline $\begin{array}{c}\text { Density } \\
\left(\mathrm{kg} / \mathrm{m}^{3}\right)\end{array}$ & 675 & 796 & 820 \\
\hline $\begin{array}{c}\text { Boiling Point } \\
(\mathrm{K})\end{array}$ & 372 & 338 & $523^{\mathrm{a}}$ \\
\hline $\begin{array}{c}\text { Heat of } \\
\text { Evaporation } \\
(\mathrm{kJ} / \mathrm{kg})\end{array}$ & 316 & 1100 & $199^{\mathrm{a}}$ \\
\hline $\begin{array}{c}\text { Specific Heat } \\
(\mathrm{kJ} / \mathrm{kg} / \mathrm{K})\end{array}$ & 2.13 & 3.46 & $2.85^{\mathrm{a}}$ \\
\hline
\end{tabular}

a : Estimated value 
temperature. Fuel temperature was measured by a chromel-alumel thermocouple covered by a stainless steel pipe of $1.5 \mathrm{~mm}$ diameter. This thermocouple was inserted through the side of the tank into its center with the thermocouple at a height of about $1 \mathrm{~mm}$ from the tank bottom.

\section{EXPERIMENTAL RESULTS}

\section{Results for Heptane}

Heptane fuel and tank temperatures histories after ignition are shown in Fig.2. The fuel temperature curve shows three distinct regions where the temperature gradient is different, if the regions just after ignition and just before the end of combustion are omitted. The first one starts about 30

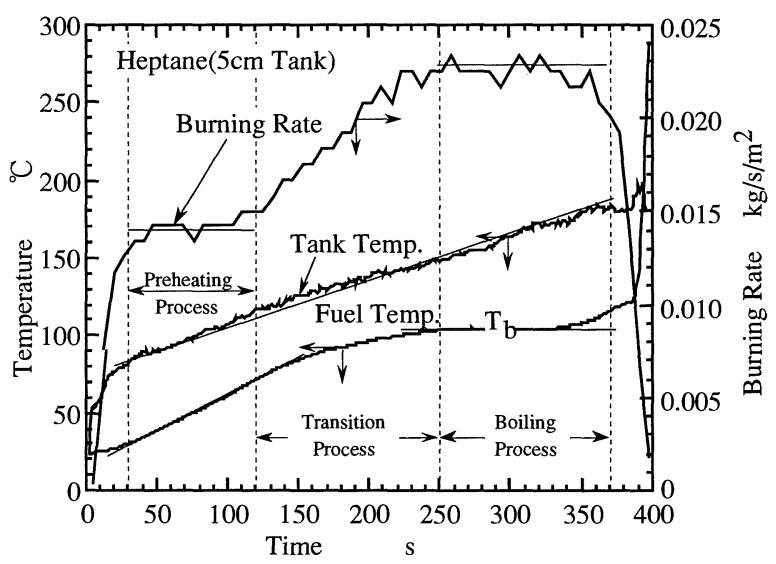

Fig.2 Experimental Results of Heptane seconds after ignition and ends at about 120 seconds. In this region the temperature gradient is almost constant (linear temperature rise). The second region starts at about 120 seconds and ends at about 250 seconds where the temperature gradient gradually becomes small and finally reaches zero. The third region starts at about 250 seconds and ends when the fuel in the tank burns out. In this region the temperature gradient is zero and the measured temperature is almost equal to the boiling point of the fuel used $\left(99^{\circ} \mathrm{C}\right)$. These three regions can be called preheating, transition and boiling processes respectively as shown in Fig.2.

To check temperature distribution in the fuel, one additional thermocouple of $1.5 \mathrm{~mm}$ diameter was inserted at the location of $5 \mathrm{~mm}$ from the tank wall and $1 \mathrm{~mm}$ from the tank bottom. It was found that fuel temperature near the wall was higher than that of the center. Maximum temperature difference was $10{ }^{\circ} \mathrm{C}$ and distinct temperature difference appeared only in the preheating process. Significant temperature difference was not observed in the transition and boiling processes. This means that measured fuel temperature near the center and bottom of the tank was the lowest temperature in the tank fuel.

To check temperature distribution at the fuel tank, two additional thermocouples of $0.1 \mathrm{~mm}$ diameter were welded at the middle and bottom of the side wall of the tank. It was found that the top of the tank always shows the maximum temperature, and there is significant temperature difference between the top and bottom of the tank. Mean temperature difference was $30{ }^{\circ} \mathrm{C}$. This 
means that the measured tank temperature near the tank top was the highest temperature of the tank.

In this paper, the boundaries of each region are obtained by drawing two straight lines on the fuel temperature curve, one for the preheating and one for the boiling process because the temperature gradients for these two processes are almost constant. The first boundary, between preheating and transition, is located where the fuel temperature curve departs from the straight line of the preheating process. The second boundary, between transition and boiling, is located where the fuel temperature curve reaches the straight line for the boiling process, or the boiling point of the fuel.

The high fuel temperature recorded after 350 seconds in Fig. 2 is due to the effect of flame approaching the thermocouples. Similar results are obtained for other fuels. Fuel temperature data higher than the boiling point of the fuel are omitted in the following calculations.

Burning (mass loss) rate history is also shown in Fig.2. The burning rate increases rapidly just after ignition and becomes constant at $0.014 \mathrm{~kg} / \mathrm{s} / \mathrm{m}^{2}$ during the preheating process - from 30 to 120 seconds after ignition. The burning rate in the transition process increases gradually and reaches a final constant value. The burning rate during the boiling process keeps a constant value of about $0.023 \mathrm{~kg} / \mathrm{s} / \mathrm{m}^{2}$. The burning rate in the boiling process is about 1.64 times that of the preheating process.

\section{Results for Methanol}

Methanol fuel and tank temperature changes after ignition are shown in Fig.3. Using the above mentioned technique, three distinct regions similar to the heptane results can be defined. The preheating process starts at about 30 seconds after ignition and ends at about 120 seconds. Here the temperature gradient is almost linear. The transition process starts at about 120 seconds and ends at about 220 seconds where the temperature gradient gradually becomes small and finally reaches zero. The boiling process (b.p. 65 ${ }^{\circ} \mathrm{C}$ ) starts from about 220 seconds and ends at about 500 seconds.

Burning rate changes are also shown in Fig.3. The burning rate increases rapidly just after ignition to a constant value of about

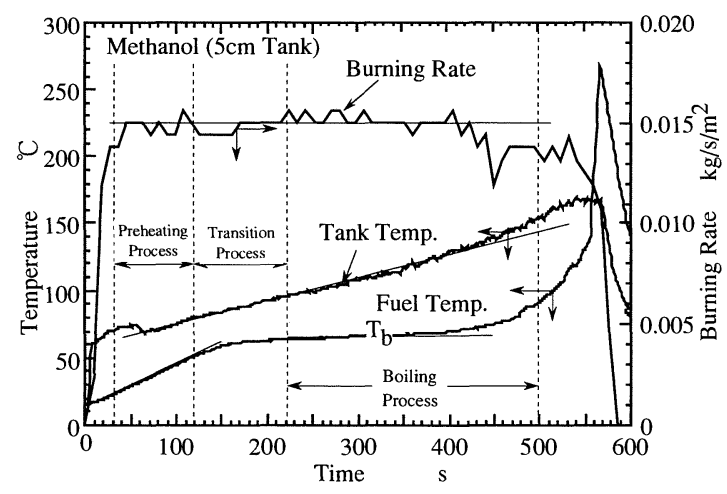

Fig.3 Experimental Results of Methanol 
$0.015 \mathrm{~kg} / \mathrm{s} / \mathrm{m}^{2}$ for each of the three processes. The distinct burning rate changes observed for heptane do not appear in the results for methanol.

\section{Results for Kerosene}

Kerosene fuel and tank temperature changes after ignition are shown in Fig.4. There is no distinct boiling process in Fig.4. This is because

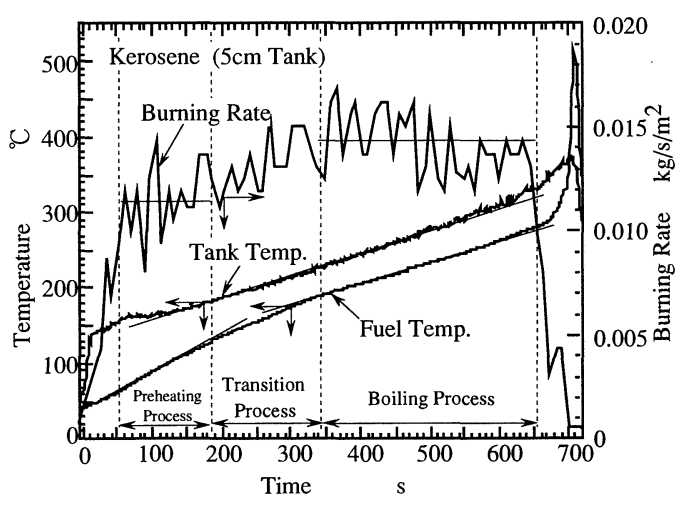

Fig.4 Experimental Results of of Kerosene kerosene is a compound fuel and light substances with low boiling temperature tend to vaporize early. As a result of the successive boil-off of the lighter fractions, the residual kerosene in the tank has a higher boiling temperature than that of fresh kerosene. Fortunately, a straight line can be drawn in the region corresponding to the boiling process in Fig.4. Thus the three regions could be defined. The preheating process starts about 50 seconds after ignition and ends at about 180 seconds. The transition process starts at about 180 seconds and ends at about 340 seconds. The boiling process starts at about 340 seconds and ends at about 650 seconds. The temperature gradients of all three processes are almost linear. The temperature gradient for preheating is the largest and the one for the boiling process is the smallest. Burning rate changes are also shown in Fig.4. The burning rate increases rapidly just after ignition, like the other fuels, and becomes a constant value of $0.011 \mathrm{~kg} / \mathrm{s} / \mathrm{m}^{2}$ during the preheating process. The burning rate in the transition process increases gradually and reaches a final, constant value. The burning rate in the boiling process has a value of about $0.014 \mathrm{~kg} / \mathrm{s} / \mathrm{m}^{2}$. The burning rate in the boiling process is about 1.27 times that of the preheating process. This increase is not marked, compared with that of heptane shown in Fig.2.

\section{DISCUSSION}

\section{Heat Flows in the Fuel Layers}

It is important to clarify the heat flows near the fuel surface because burning velocity of a pool fire strongly depends on these heat flows. Major heat flows near the fuel surface are shown in Fig.5. There is a so called "vaporizing layer" at the top of fuel layer. Vaporizing layer is usually considered as very thin layer and fuel temperature is equal to the boiling point. In Fig.5, a certain thickness is given to represent the vaporizing layer. In Fig.5, flame front, recirculation 
zone for the combustion gas side, vortexes formed by natural convection of fuel and vertical temperature profile are also illustrated to understand pool fire phenomena by referring and considering the results of a few researchers $[9,11,13]$. Under the vaporizing layer, there is a preheating layer where fuel temperature varies exponentially. Under these two layers, there is a "bottom" fuel layer where fuel temperature usually dose not vary in the vertical direction, namely it is almost constant.

Heat balances for these layers must be considered in turn. The heat balance for the

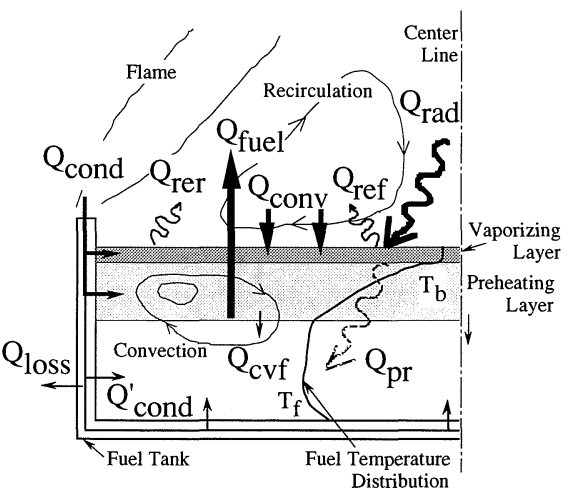

Fig.5 Major Heat Flows near Fuel Surface vaporizing and preheating layer is expressed by equation (1) $[9,11,13]$.

$\mathrm{Q}_{\text {rad }}+\mathrm{Q}_{\text {conv }}+\mathrm{Q}_{\text {cond }}=\mathrm{Q}_{\text {fuel }}+\mathrm{Q}_{\text {rer }}+\mathrm{Q}_{\text {ref }}+\mathrm{Q}_{\text {cvf }}$

Major heat gain terms in equation (1) are radiation from the flame, $\mathrm{Q}_{\mathrm{rad}}$, convection due to combustion gas, $Q_{\text {conv }}$, and conduction from the tank wall, $Q_{\text {cond }}$. Major heat loss terms in equation (1) are the total heat needed for fuel vaporization, $Q_{\text {fuel }}$, radiation from the fuel surface to the surroundings, $Q_{\text {rer }}$, reflection of a portion of $Q_{\text {rad }}, Q_{\text {ref }}$, and fuel convection that carries heat to the bottom fuel layer, $\mathrm{Q}_{\text {cvf }}$.

The total heat needed for fuel vaporization, $Q_{\text {fuel }}$, is expressed by equation $(2) \quad[9,11,13]$.

$$
\mathrm{Q}_{\mathrm{fuel}}=\mathrm{Q}_{1}+\mathrm{Q}_{2}=\mathrm{w}_{\mathrm{f}} \mathrm{C}_{\mathrm{fpm}}\left(\mathrm{T}_{\mathrm{b}}-\mathrm{T}_{\mathrm{fo}}\right)+\mathrm{w}_{\mathrm{f}} \Delta \mathrm{H}_{\mathrm{f}}
$$

where $Q_{1}=w_{f} C_{f p m}\left(T_{b}-T_{f}\right)$ is the heat needed to increase the fuel temperature from its initial temperature, $\mathrm{T}_{\mathrm{f} 0}(\mathrm{~K})$, to the boiling point, $\mathrm{T}_{\mathrm{b}}(\mathrm{K}), \mathrm{w}_{\mathrm{f}}$ is the mass burning (mass loss) rate $(\mathrm{kg} / \mathrm{s})$, and $\mathrm{C}_{\mathrm{fpm}}$ is the mean specific heat of the fuel between $\mathrm{T}_{\mathrm{f0}}$ and $\mathrm{T}_{\mathrm{b}} \cdot \mathrm{Q}_{2}\left(=\mathrm{w}_{\mathrm{f}} \Delta \mathrm{H}_{\mathrm{f}}\right)$ is the heat needed to vaporize the fuel, and $\Delta \mathrm{H}_{\mathrm{f}}$ is the heat of evaporation of the fuel $(\mathrm{kJ} / \mathrm{kg})$. The heat balance for the bottom fuel layer is expressed by equation (3) .

$\mathrm{m}_{\mathrm{fl}} \mathrm{C}_{\mathrm{fpm}}\left(\mathrm{T}_{\mathrm{fl}}-\mathrm{T}_{\mathrm{f}}\right)=\mathrm{Q}_{\mathrm{pr}}+\mathrm{Q}_{\mathrm{cvf}}+\mathrm{Q}_{\text {cond }}^{\prime}$

where $m_{f 1}$ is residual mass of fuel in the bottom fuel layer, $C_{f p m}$ is the mean specific heat of the fuel. $\mathrm{T}_{\mathrm{f} 1}$ and $\mathrm{T}_{\mathrm{f}}$ are fuel temperature. Heat input terms in equation (3) and shown in Fig. 8 are flame radiation that passes the vaporizing and preheating layer, $Q_{p r}$, fuel convection, $Q_{c v f}$ and conduction from the bottom tank wall, $\mathrm{Q}_{\text {cond }}^{\prime}$. Since there is no major heat loss term, the bottom 
fuel layer will be warmed up by the three heat input terms. We should also notice that the bottom fuel layer exchanges heat with the vaporizing and preheating layer through only $\mathrm{Q}_{\mathrm{cvf}}$. This means that if there is no distinct fuel convection, there is no direct heat exchange between the bottom fuel layer and the vaporizing and preheating layer.

\section{Consideration in the Heat Balance Equation}

To find out reasons for unsteady burning rates, a few assumptions must be made and all experimental data must be used for this purpose.

From tank temperature curves in Figs. 2, 3 and 4, it is found that rates of tank temperature increase at the preheating, transition and boiling processes are almost constant. Namely, the mean rate of increase for heptane is about $0.31^{\circ} \mathrm{C} / \mathrm{s}$, that for methanol is about $0.16^{\circ} \mathrm{C} / \mathrm{s}$ and that for kerosene is about $0.29^{\circ} \mathrm{C} / \mathrm{s}$. These increase rates of the tank temperature are also depends on heat gain terms $Q_{\text {rad }}, Q_{\text {conv }}$ and $Q$ cond for the vaporizing and preheating layer in equation (1). From these experimental results, it can be considered that equation (1) is nearly constant, namely $\mathrm{Q}_{\text {rad }}+\mathrm{Q}_{\text {conv }}+\mathrm{Q}_{\text {cond }}=\cdot \cdot . \fallingdotseq$ const..

On the other hand, $\mathrm{Q}_{\text {fuel }}$ is the largest heat term among heat loss terms in heat balance equation (1) and greater than $10 \mathrm{~W}$. Other terms $\mathrm{Q}_{\text {rer }}$ and $\mathrm{Q}_{\text {ref }}$ are not so large because the emissivity of fuel liquid surface is usually grater than 0.9 and fuel surface temperature is equal to the boiling point. $\mathrm{Q}_{\text {rer }}$ and $\mathrm{Q}_{\text {ref }}$ are a few $\mathrm{W}$ at the largest. $\mathrm{Q}_{\mathrm{rer}}$ and $\mathrm{Q}_{\text {ref }}$ can be neglected because they are small compared with $\mathrm{Q}_{\text {fuel }}$ and they are considered as almost constant values. Last term $\mathrm{Q}_{\text {cvf }}$ depends on a scale of fuel convection. If a scale of fuel convection is large, $\mathrm{Q}_{\mathrm{cvf}}$ reduce a burning rate remarkably. Fortunately, $\mathrm{Q}_{\mathrm{cvf}}$ can be neglected because there was no remarkable reduction of the burning rate in this experiment.

Finally, equation to be considered is obtained from equation (1) and (2). That is to say,

$\mathrm{Q}_{\text {fuel }}=\mathrm{w}_{\mathrm{f}} \mathrm{C}_{\mathrm{fpm}}\left(\mathrm{T}_{\mathrm{b}}-\mathrm{T}_{\mathrm{fo}}\right)+\mathrm{w}_{\mathrm{f}} \Delta \mathrm{H}_{\mathrm{f}} \fallingdotseq$ const.

In equation (4), experimental data for $\mathrm{w}_{\mathrm{f}}$ and $\mathrm{T}_{\mathrm{f}}$, shown in the Figs. from 2 to 4 , were used in the following calculations. Other fuel properties were mainly extracted from Table 1.

\section{Evaporation Heat Change of Heptane}

The calculated total heat for evaporation, $\mathrm{Q}_{\text {fuel }}$, and of preheating heat, $\mathrm{Q}_{1}$ are shown in Fig.6. From Fig.6, $\mathrm{Q}_{\text {fuel }}$ stays at an almost constant value of around $13 \mathrm{~W}$. On the other hand, $\mathrm{Q}_{1}$ has a peak at between 10 and 30 seconds after ignition and gradually decreases because $T_{f}$ starts to 
rise toward the boiling point, $\mathrm{T}_{\mathrm{b}}$. In the preheating process, between 30 and 70 seconds after the ignition, the maximum $\mathrm{Q}_{1}$ is $30 \%$ of $\mathrm{Q}_{\text {fuel }}$. This percentage gradually decreases to 0 because $T_{f}$ becomes equal to $T_{b}$ at the onset of boiling. Extra fuel can be vaporized because of the decreasing preheating requirement, $Q_{1}$, and because $Q_{\text {fuel }}$ is almost constant. This is one reason for the increased burning rate of heptane during the boiling process. The ordinate in Fig. 6 has the same scale as Figs.7 and

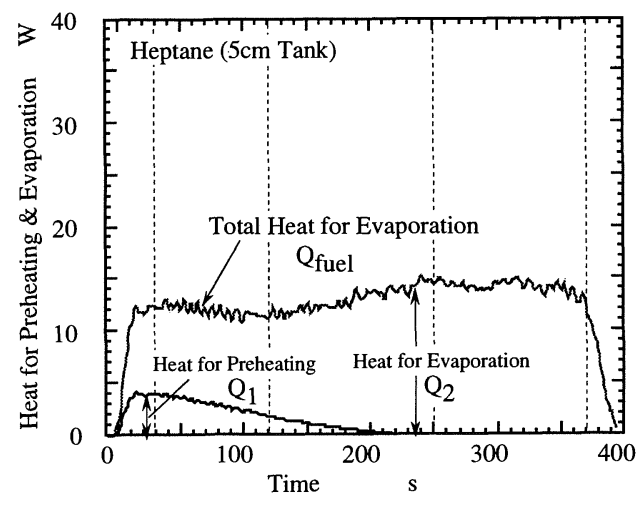
8 for easy comparison.

Fig.6 Evaporation Heat of Heptane

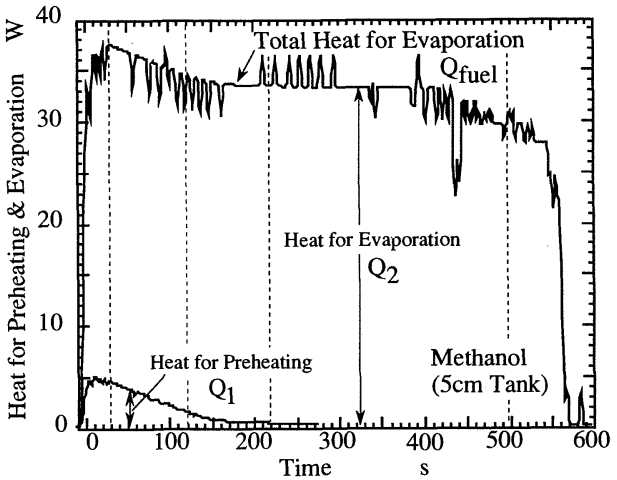

Fig.7 Evaporation Heat of Methanol 2.6 times bigger than that of heptane. In the preheating process, the maximum $\mathrm{Q}_{1}$ is only $10 \%$ of $\mathrm{Q}_{\text {fuel }}$. As a result, $\mathrm{Q}_{\text {fuel }}$ is not greatly different with or without $Q_{1}$ subtracted. This is one reason the burning rate of methanol did not show a distinct change.

\section{Evaporation Heat Change of Kerosene}

As mentioned above, kerosene changes it's properties such as $T_{b}, \Delta H_{f}$ and so on, because kerosene is a compound fuel. $\mathrm{Q}_{\text {fuel }}$ and $\mathrm{Q}_{1}$ for kerosene, obtained by using fixed kerosene

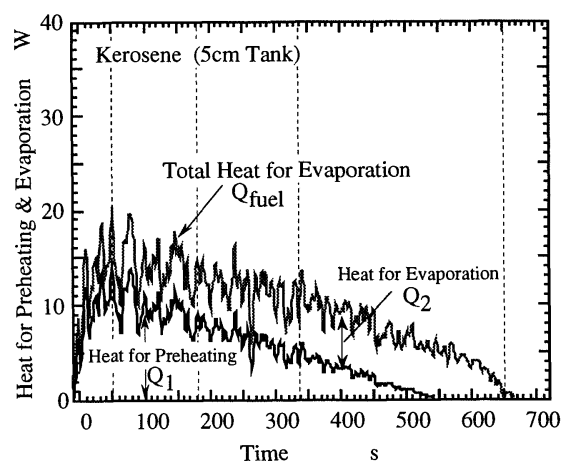

Fig.8 Evaporation Heat of Kerosene 
properties, are in Table 1 and shown in Fig.8. The following discussion, of necessity, contains a lot of estimation. From Fig.8, $\mathrm{Q}_{\text {fuel }}$ shows an almost constant value of around $14 \mathrm{~W}$ in the preheating and transition processes. $\mathrm{Q}_{1}$ has a peak value of around $12 \mathrm{~W}$ at around 50 seconds after ignition and gradually decreases, as the other fuels do, because $T_{f}$ starts to rise toward $T_{b}$. $Q_{1}$ is a larger percentage of $\mathrm{Q}_{\text {fuel }}$ than for the other fuels. The large value for $\mathrm{Q}_{1}$ is due to the high mean boiling point $\left(\mathrm{T}_{\mathrm{b}}=523 \mathrm{~K}\right)$ compared to the other fuels. Thus, we can imagine that, in a kerosene fire, almost all the heat is consumed in preheating fuel. If we could use more correct properties for kerosene, such as $\mathrm{T}_{\mathrm{b}}$ and $\Delta \mathrm{H}_{\mathrm{f}}$ for the boiling process, the curve of total heat for evaporation might become more flat throughout the boiling process as that of heptane is.

Heat for preheating in Fig. 8 gradually decrease and becomes 0 in the middle of boiling process where $T_{f}$ reaches $T_{b}$. Thus extra fuel can be vaporized according to the decreased heat of $Q_{1}$ if $\mathrm{Q}_{\text {fuel }}$ is almost constant with a value around $14 \mathrm{~W}$. This may be one reason for the increased burning rate of kerosene just like heptane.

\section{Introduction of Maximum Burning Rate Ratio}

The above discussion, suggests the concept of a maximum burning rate ratio that will serve to estimate the increased burning rate of various fuels. For any liquid fuel at room temperature, maximum and minimum burning rates can be obtained from the equation (1) . Namely, if $T_{f}$ is equal to $\mathrm{T}_{\mathrm{b}}$ in equation (1) , the maximum burning rate, $\mathrm{w}_{\mathrm{fmax}}$, can be obtained. In like manner, putting room temperature $\left(\mathrm{T}_{\mathrm{ff}}=298 \mathrm{~K}\right)$ into $\mathrm{T}_{\mathrm{f}}$, a minimum burning rate, wfmin, can be obtained. Assuming the total heat for evaporation $\left(\mathrm{Q}_{\mathrm{f}}\right)$ is constant, the following equation (5) for maximum burning rate ratio, $\mathrm{MBRR}_{0}$ for short, is introduced.

$$
\begin{aligned}
& \operatorname{MBRR}_{0}=\mathrm{w}_{\mathrm{fmax}} / \mathrm{w}_{\mathrm{fmin}} \\
& =\mathrm{C}_{\mathrm{fpm}}\left(\mathrm{T}_{\mathrm{b}}-\mathrm{T}_{\mathrm{fo}}\right) / \Delta \mathrm{H}_{\mathrm{f}}+1
\end{aligned}
$$

$\mathrm{MBRR}_{0} \mathrm{~s}$ for various fuels are shown in Fig.9. From Fig.9, $\mathrm{MBRR}_{0}$ s for alcohols and other fuels tend to become large when the number of atoms in the fuel increase. Experimental

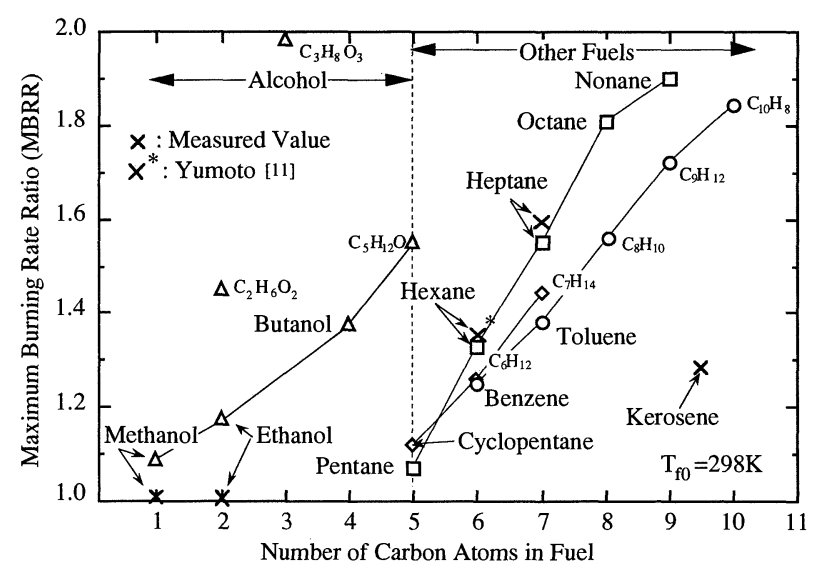

Fig.9 Maximum Burning Rate Ratio of Various Fuels 
results for heptane and methanol are shown by cross marks on Fig.9.

The $\mathrm{MBRR}_{0}$ for heptane is 1.56 which is almost equal to the experimental value. The $\mathrm{MBRR}_{0}$ for methanol is 1.08 which is also almost equal to the experimental value of 1 . The $M_{B R R_{0}}$ for kerosene is 4.22 if we use fuel properties shown in Table 1. Application of the $\mathrm{MBRR}_{0}$ concept to compound fuels like kerosene should be reconsidered, depending on the outcome of future work.

Recently additional experiments for ethanol and benzene were done by the author. The $\mathrm{MBRR}_{0}$ for benzene is 1.26 but, due to its relatively high burning velocity and severe flame radiation, a stable burning rate during the preheating process could not be defined and observed. Thus, the experimental result for ethanol only is shown by a cross mark on Fig.9.

The $\mathrm{MBRR}_{0}$ for hexane is 1.33 . Yumoto [11] did a hexane pool fire experiment by using a Pyrex glass tank with $3 \mathrm{~cm}$ diameter and $6 \mathrm{~cm}$ depth. He observed two stable burning rates, 0.02 and $0.016 \mathrm{~kg} / \mathrm{s} / \mathrm{m}^{2}$ during the preheating process. He concluded that the smaller burning rate was affected by convection of the fuel in the tank. The Maximum burning rate during the boiling process was $0.027 \mathrm{~kg} / \mathrm{s} / \mathrm{m}^{2}$. The measured MBRR without convection effect for hexane is 1.35 . It is plotted by cross with a star $\left(x^{*}\right)$ mark in Fig.9.

\section{CONCLUSIONS}

Burning rates, fuel temperatures and tank temperatures of small heptane, methanol and kerosene pool fires were measured during unsteady combustion. Experimental results and the above discussion allow the following conclusions :

1. Three major processes, so called preheating, transition and boiling processes, were found from the fuel temperature change curves of small pool fires during unsteady combustion.

2. Burning rates of heptane and kerosene increase when fuel and tank temperatures go up. The burning rates for heptane during the boiling process is about 1.64 as much as those during the preheating process. It is 1.3 times as much for kerosene.

3. Preheating, transition and boiling processes were easily found from the fuel temperature change curves of the methanol pool fire. Nevertheless methanol does not show a distinct increase of burning rate.

4. The reason for various burning rate changes of small pool fires are clearly explained by the calculation of fuel evaporation using measured burning rates and fuel temperatures. Heptane and kerosene fires change their burning rates because both evaporation heats and preheating heat are not large. The evaporation heat of methanol is the largest and it is about three or five times bigger than that of heptane and kerosene. This is one of the reasons for the constant burning rate of methanol.

5. From the above discussion, the concept of maximum burning rate ratio $\left(\mathrm{MBRR}_{0}\right)$ is introduced 
to explain the burning rate change of various fuels. $\mathrm{MBRR}_{0}$ becomes larger as the number of carbon atoms in fuel increases.

Finally, the above mentioned phenomena will happen when the heat supply by convection and conduction is not small compared with that supplied by radiation. In medium and large size pool fires, sufficient heat will be supplied from the flame, mainly by radiation, so that the above mentioned preheating and transition processes may not easily be found. In small pool fires, burning rates are strongly affected by circumferential conditions such as fuel and tank temperatures. This may be one reason for various burning rates obtained by experiments using the same tank size and fuel.

\section{ACKNOWLEDGMENTS}

The author wish to thank to Mr. Synya Sonoda and Mr. Akira Kawabata for their help and Dr. John A. Rockett for editorial assistance.

\section{REFERENCES}

1. Thomas, P.H.,"Some Experiments on Buoyant Diffusion Flames", Combustion and Flame, Vol.5, pp.359-367, 1961.

2. Akita, K. and Yumoto, T.,"Heat Transfer in Small Pools and Rates of Burning of Liquid Methanol", Tenth Symp. (Inter.) on Combustion, The combustion Institute, Pittsburgh, pp.943948, 1965.

3. Yumoto, T.,"Heat Transfer from Flame to Fuel Surface in Large Pool Fires", Combustion and Flame, Vol.17, pp.108-110, 1971.

4. McCaffrey, B. J.,"Purely Buoyant Diffusion Flames : Some Experimental Results", Heptane Pool Fires", Fire Technology, Vol.24 (1) , pp.33-47, 1979.

5. Cetegen, B. M., Zukoski, E. E. and Kubota, T.,"Entrainment and Flame Geometry of Fire Plumes", NBS-GCR-82-402 (NBS,Washington, D.C.), pp.1-203, 1982.

6. Babrauskas, V., "Estimating Large Pool Fire Burning Rates", Fire Technology, Vol.19-4, pp.251-261, 1983.

7. Mudan, K. S.,"Thermal Radiation Hazards from Hydrocarbon Pool Fires", Prog. Energy and 
Combust. Sci., Vol.10, pp.59-80, 1984.

8. Koseki. H. and Yumoto, T.,"Air Entrainment and Thermal Radiation from Heptane Pool Fires", Fire Technology, Vol.24 (1) , pp.33-47, 1988.

9. Ndubizu, C. C., Ramaker, D.E., Tatem, P.A., and Williams, F.W.,,"A Model of Freely Burning Pool Fires", Combustion Science and Technology, Vol.31, pp.233-247 1983.

10. Crocker, W. P. and Napier, D.H.,"Thermal Radiation Hazards of Liquid Pool Fires and Tank Fires", I.CHEM.E. Symposium Series No.97, pp.159-184, 1986.

11. Yumoto, T., "Burning Rate and Thermal Radiation in Surface Combustion (Japanese) ", Doctoral Thesis, pp.57, 1987.

12. Hayasaka, H., Koseki, H., and Tashiro, Y.,"Radiation Measurements in Large-Scale Kerosene Pool Flames using High-Speed Thermography", Fire Technology, Vol.28 (2) , pp.110-122, 1992.

13. Hamins, A., Klassen, M. E., Gore, J. P., Fischer S. J. and Kashiwagi, T., "Heat Feedback to the fuel surface in pool fires", Combustion Science and Technology, Vol.10, pp.1-27, 1993.

14. Hikita, T. and Akita, K., "Outline of Combustion (Japanese) ", Corona Publishing Co., LTD., Tokyo, pp.190-199, 1971. 